\title{
Closed system for bovine oocyte vitrification
}

\author{
Helena Ševelová, Miloslava Lopatářová \\ Department of Reproduction, Ruminant and Swine Clinic, Faculty of Veterinary Medicine, \\ University of Veterinary and Pharmaceutical Sciences Brno, Czech Republic \\ Received February 29, 2012 \\ Accepted April 11, 2012
}

\begin{abstract}
The aim of our study was to develop a vitrification carrier for bovine oocyte cryopreservation. The carrier was to be cheap enough, elementary in its construction and meet contemporary requirements for a safe closed system. In a closed system, a cell is prevented from direct exposure to liquid nitrogen, thus minimizing the risk of cross-contamination. Furthermore, two questions regarding the proper vitrification technique were resolved: if it is necessary to partially denude the oocytes before the vitrification process or whether intact cumulus oocyte complexes should be frozen; and if it is more advantageous to preheat the vitrification solutions to female body temperature $\left(39^{\circ} \mathrm{C}\right)$ or to keep them at room temperature. Our results show that it is better to partially denude the oocytes prior to vitrification because cryopreserved intact cumulus oocyte complexes often proved dark, non-homogeneous or fragmented cytoplasm after warming, with many of them having visibly widened perivitelline spaces or fractured zonae pellucidae as a result of extensive damage during vitrification. Consequently, intact cumulus oocyte complexes showed significantly lower numbers of cleavage stage embryos on Day 3 compared to partially denuded oocytes $(7.4 \%$ and $26 \%$, respectively). On the other hand, the survival rate and following development of fertilized oocytes in preheated vitrification solution were equal to results reached at room temperature conditions. In conclusion, results achieved with the newly developed carrier were comparable to previously published studies and therefore they could be recommended for common use.
\end{abstract}

Cattle, cryopreservation, cumulus cells, preheating

Cryopreservation of farm animal embryos is nowadays a widely used routine technique (Betteridge et al. 2006). However, oocyte cryopreservation produced insufficient results for many years (Chen et al. 2003).

Two basic methods of cryopreservation are commonly used; slow freezing and vitrification. Both of them prevent intracellular ice crystal formation and solution effect during the freezing stage as well as osmotic shock during subsequent warming. To prevent the above mentioned damage of embryos, additional chemicals (cryoprotectants) are applied.

When slow freezing is performed, low concentrations of cryoprotectant chemicals and long freezing time with the assistance of special equipment are essential. To the contrary, vitrification requires high cryoprotectant concentrations and instant refrigeration using liquid nitrogen. During this process, water does not crystallize but transforms into solid state with an amorphous structure and its volume is not expanded (Jain and Paulson 2006). Better results are achieved when vitrification technique is used freezing oocytes (Ambrosini et al. 2006).

Direct transition of water into the amoprhous solid state using vitrification technique is conditioned by instant freezing (Jain and Paulson 2006). The sample is usually deposited in an appropriate carrier and immersed in liquid nitrogen. It still poses a risk of possible bacterial (Bielanski et al. 2003) and viral infections (Bielanski et al. 2000). Mainly in human reproduction, "closed vitrification systems" are implemented as means of prevention in order to keep the carrier hermetically sealed within an additional casing. Based on research data, open vitrification systems have shown results comparable to closed systems (Kuwayama et al. 2005; Larman et al. 2006).

Address for correspondence:

Doc. MVDr. Miloslava Lopatářová, CSc.

Department of Reproduction, Ruminant and Swine Clinic

University of Veterinary and Pharmaceutical Sciences

Phone: + 420541562323

Palackého tř. 1/3, 61242 Brno, Czech Republic 
These safe carriers are commercially produced for human reproduction; however, they are very expensive. The objective of this study was to develop and test a cheap carrier, appropriate enough for closed systems and usable for bovine oocyte vitrification. Further aims included resolving the following questions: what temperature should be maintained while handling cells; and whether it is more advantageous to cryopreserve either intact cumulus oocyte complexes (COC) or partially denuded oocytes.

\section{Materials and Methods}

Chemicals were obtained from Sigma-Aldrich (Missouri, USA) unless otherwise stated. The ambient temperature in the laboratory was adjusted to $25 \pm 1{ }^{\circ} \mathrm{C}$.

Collection of oocytes and in vitro maturation

All procedures were performed following the method described by Hlavicová et al. (2010), with minor modifications only. For maturation, Control Group COCs were cultured for $24 \mathrm{~h}$, COCs from Groups 2 and 3 were cultured for $22 \mathrm{~h}$.

In vitro fertilization

All procedures were performed following the method described by Hlavicová et al. (2010), with minor modifications only. For removing the dead spermatozoa and remaining cumulus cells, a mechanical method of vortexing for $15 \mathrm{~s}$ in vortex medium described by Modina et al. (2004) was used (M199 supplemented with 5\% calf serum and buffered with 20 mM HEPES).

\section{Carrier}

The carrier was obtained from $0.25 \mathrm{ml}$ plastic straw (IMV Technologies). The straw had to be drawn carefully over the flame of alcohol burner in order to lengthen it by additional $20 \%$; then cut with a razor-blade in its narrowest spot. The narrow ends of both halves were then cut obliquely, in order to form a little site at the inner surface of the straw, where oocytes were deposited during the vitrification process. Only by drawing the straw, a sufficiently thin plastic layer is ensured to reduce the influence of its thermal insulation properties on freezing speed during vitrification.

To prevent cells from direct exposure to liquid nitrogen, the carrier was afterwards inserted into extra $0.5 \mathrm{ml}$ straw (Minitübe). A metal weight, obtained from steel wire (Graupner, $2 \mathrm{~mm}$ diameter) cut into $0.5 \mathrm{~cm}$ pieces, was placed inside the $0.5 \mathrm{ml}$ straw from the cotton plug end. This end was thereafter sealed up with burner heated tweezers.

\section{Vitrification and warming}

Vitrification and warming of COCs followed the method described by Vajta et al. (1998) with several modifications. One of them concerned replacing DMSO, dangerous for its staff toxicity, by less hazardous PROH (Stachecki et al. 2008). Oocytes were firstly washed and equilibrated in a holding medium (HM) consisting of TCM199-HEPES supplemented with $20 \%$ foetal calf serum (FCS) for $5 \mathrm{~min}$. After equilibration, two oocytes were always incubated for $30 \mathrm{~s}$ (or $45 \mathrm{~s}$ in Group 3 in Experiment 2) in first vitrification solution, composed of $10 \%$ ethylene glycol $(\mathrm{EG})+10 \%$ propylene glycol $(\mathrm{PROH})$ dissolved in $\mathrm{HM}$, and subsequently transferred into second vitrification solution, composed of $20 \% \mathrm{EG}+20 \% \mathrm{PROH}+0.5 \mathrm{M}$ sucrose dissolved in $\mathrm{HM}$ and deposited with a minimum amount of second vitrification solution onto the carrier. This carrier was later inserted into the outer straw previously fixed in a polystyrene box filled with liquid nitrogen. The outer straw had to be attached vertically to the wall of the box, in order to keep the open end about $1 \mathrm{~cm}$ above the nitrogen level. Immediately after the carrier insertion, the open end of the straw had to be sealed up with burner heated tweezers. The time span of $30 \mathrm{~s}$ ( or $45 \mathrm{~s}$ within Group 3 in Experiment 2) between the oocyte exposure to second vitrification solution and the carrier insertion into the outer straw should not be exceeded.

Warming was performed by placing the end of the carrier, where oocytes had been previously deposited, directly into first warming solution composed of HM supplemented with $0.25 \mathrm{M}$ sucrose for 5 min. Oocytes were thereafter transferred into second warming solution, composed of HM containing $0.15 \mathrm{M}$ sucrose for another 5 min. After two subsequent washes in HM for 5 min each, oocytes were transferred back into maturation 4-well plates (NUNC), matured for an additional $2 \mathrm{~h}$ and fertilized.

Vitrification and warming solutions were pipetted into 4-well plates at $500 \mu \mathrm{l}$ each (only the first warming solution at $1 \mathrm{ml}$ ). Solutions were preheated on a $39^{\circ} \mathrm{C}$ hot plate for $15-20 \mathrm{~min}$ (except for vitrification solutions within the third group in Experiment 2, equilibrated to an ambient temperature) before use.

Experimental design

Experiment 1

Oocytes were separated randomly into three groups. Group 1 (Control) was matured in vitro for $24 \mathrm{~h}$; then fertilized. Groups 2 and 3 were matured for $22 \mathrm{~h}$ and vitrified. Within Group 2, intact COC were vitrified, whereas within Group 3, COC were vortexed for $15 \mathrm{~s}$ before the insertion into HM, wherefore only two to four layers of cumulus cells remained on the surface. 


\section{Experiment 2}

Oocytes were separated randomly into three groups. First group (control) was matured in vitro for $24 \mathrm{~h}$; then fertilized. Groups 2 and 3 were partially denuded $22 \mathrm{~h}$ after the onset of maturation by vortexing for 15 s, wherefore only two to four layers of cumulus cells remained on the surface, and vitrified. Within Group 2 , vitrification solutions were preheated on a $39{ }^{\circ} \mathrm{C}$ hot plate for $15-20 \mathrm{~min}$ and oocytes from Group 2 were then placed into the first and second vitrification solution for $30 \mathrm{~s}$. Within Group 3, vitrification solutions were equilibrated to an ambient temperature and oocytes were placed into the first and second vitrification solution for $45 \mathrm{~s}$.

Within Group 3, relevant time interval was lengthened due to the fact that membrane permeability is lower at room temperature than at $39{ }^{\circ} \mathrm{C}$ (Mazur 1970; Ambrosini et al. 2006). In order to reach comparable penetration of cryoprotectants into the cell at lower temperatures it was necessary to prolong exposure time. Aforementioned $45 \mathrm{~s}$ match the reference of exposure intervals previously stated in Chian et al. (2009), who used similar vitrification solutions at room temperature.

Statistical analysis

The obtained data were analyzed by the $\chi 2$ test (Fisher's exact test, $P<0.001$ and $P<0.02$ ).

\section{Experiment 1}

\section{Results}

Vitrified intact COCs often proved dark, non-homogeneous or fragmented cytoplasm after warming and numerous COCs had visibly widened perivitelline spaces or fractured zonae pellucidae. Significantly lower cleavage rate on Day 3 (Table 1) was induced by oocyte degeneration on Day 1 after warming.

Table 1. Effect of partial denudation on the development of vitrified-warmed bovine oocytes

\begin{tabular}{lccccc}
\hline \multirow{2}{*}{ Group } & \multirow{2}{*}{ No. oocytes } & Day 3 & Day 6 & Day 8 & \\
\cline { 3 - 5 } & & Cleaved (\%) & Morulae (\%) & Blastocysts (\%) & Expansion (\%) \\
\hline Control & 230 & $171(74.3)^{\mathrm{a}}$ & $77(33.5)^{\mathrm{a}}$ & $44(19.1)^{\mathrm{a}}$ & $30(13)^{\mathrm{a}}$ \\
Partially denuded & $196^{\mathrm{N}}$ & $51(26)^{\mathrm{b}}$ & $10(5.1)^{\mathrm{b}}$ & $2(1)^{\mathrm{b}}$ & $2(1)^{\mathrm{b}}$ \\
Intact COCs & $189^{\mathrm{N}}$ & $14(7.4)^{\mathrm{c}}$ & $4(2.1)^{\mathrm{b}}$ & $1(0.5)^{\mathrm{b}}$ & 0 \\
\hline
\end{tabular}

$\mathrm{N}$ - number of oocytes recovered after warming; different letters differ significantly $(\mathrm{a}, \mathrm{b}, \mathrm{c}: P<0.001)$

\section{Experiment 2}

There was no difference in development of fertilized oocytes, which were handled in preheated vitrification solution or in vitrification solution equilibrated to ambient temperature (Table 2). Based on the amount of cleavage stage embryos on Day 3, there was no difference in survival and fertilization ability.

Table 2. Effect of vitrification solutions preheating on the development of vitrified-warmed bovine oocytes

\begin{tabular}{lccccc}
\hline \multirow{2}{*}{ Group } & \multirow{2}{*}{ No. oocytes } & Day 3 & Day 6 & Day 8 & \\
\cline { 3 - 5 } & & Cleaved (\%) & Morulae (\%) & Blastocysts (\%) & Expansion (\%) \\
\hline Control & 121 & $83(68.6)^{\mathrm{a}}$ & $38(31,4)^{\mathrm{a}}$ & $19(15,7)^{\mathrm{a}}$ & $11(9.1)^{\mathrm{x}}$ \\
$39^{\circ} \mathrm{C}$ & $105^{\mathrm{N}}$ & $27(25.7)^{\mathrm{b}}$ & $6(5.7)^{\mathrm{b}}$ & $2(1.9)^{\mathrm{b}}$ & $1(1)^{\mathrm{y}}$ \\
$25 \pm 1{ }^{\circ} \mathrm{C}$ & $104^{\mathrm{N}}$ & $21(20.2)^{\mathrm{b}}$ & $5(4.8)^{\mathrm{b}}$ & $1(1)^{\mathrm{b}}$ & 0 \\
\hline
\end{tabular}

$\mathrm{N}$ - number of oocytes recovered after warming; different letters differ significantly (a, b, c: $P<0.001, \mathrm{x}, \mathrm{y}: P<0.02)$

\section{Discussion}

Better results are achieved when vitrification technique is used for freezing oocytes compared to slow freezing (Ambrosini et al. 2006). This is most likely caused by 
oocyte chilling injury, significant damage following exposure to low but not freezing temperatures, a phenomenon that accompanies the slow-freezing method (Arav et al. 1996). This damage concerns in particular cell membranes. In the lipid phase transition, some membrane parts become solidified, separated ("lipid phase separation") leading to ultimate disruption of membrane function (Quinn 1985). Furthermore, chilling injury affects the cytoskeleton, especially the spindle microtubules in MII oocytes, causing them to disassemble. During the warming phase the spindle re-forms, often incorrectly. This leads to consequent aneuploidy resulting in embryo loss (Chen et al. 2003). Chilling injury, devastating for the spindle, is noticeable mostly at temperatures around $0{ }^{\circ} \mathrm{C}$ (Martino et al. 1996). Even the cooling of the oocyte to $25^{\circ} \mathrm{C}$ leads to abnormal spindle formations (Aman and Parks 1994).

Nevertheless, as Vajta et al. (2009) write, the survival of vitrified oocyte is determined by a number of factors and the effect on the overall spindle condition should not be overestimated when compiling the protocol. This fact is also supported by results from MII stage oocyte cryopreservation quite comparable to GV stage (in which the spindle is not yet assembled) oocyte cryopreservation results (Fuku et al. 1992; Kubota et al. 1998; Zhou et al. 2010). Our data confirmed that because the survival rate and following development of fertilized oocytes in preheated vitrification solution were equal to results reached at room temperature conditions.

Apart from the vitrification solution temperature value, we had to solve another question: if it is more advantageous to partially denude the oocytes before the vitrification process, or whether intact cumulus oocyte complexes should be frozen. Cumulus cell in cattle are often considered essential for maturation (Im et al. 1996) and fertilization (Chian et al. 2009). It is possible to freeze completely denuded oocytes but it requiers a unique composition of manipulation medium leading to a lower blastocyst rate (Modina et al. 2004). A complete cumulus may obstruct penetration of cryoprotectants into oocytes (Hyttel et al. 2000) and affects lipid phase transition during the chilling procedures, modifying the dynamic response of cytoskeleton and plasma membrane (Bogliolo et al. 2007). This corresponds with our results. Based on the morphological condition of oocyte cytoplasm and cumulus cells after warming, the significantly lower amount of cleavage stage embryos on Day 3 from vitrified-warmed intact cumulus oocyte complexes was a clear consequence of more frequent damage during vitrification and the resultant decrease in survival and fertilization ability.

The achievements of vitrification with our newly developed carrier are comparable to results achieved by following research teams using similar vitrification protocol and open carriers (Luna et al. 2001; Diez et al. 2002; Vieira et al. 2002; Modina et al. 2004; Albarracín et al. 2005; Morató et al. 2008a, 2008b, 2008c; and Hou et al. 2009). Hence, we can declare this new carrier a safe variant for bovine oocyte vitrification, which is inexpensive to manufacture from affordable components.

\section{Acknowledgement}

This study was supported by Internal Grant Agency (IGA) 12/2011/FVL of the University of Veterinary and Pharmaceutical Sciences, Brno, Czech Republic.

\section{References}

Albarracín JL, Morató R, Rojas C, Mogas T 2005: Effects of vitrification in open pulled straws on the cytology of in vitro matured prepubertal and adult bovine oocytes. Theriogenology 63: 890-901

Aman RR, Parks JE 1994: Effects of cooling and rewarming on the meiotic spindle and chromosomes of in vitro-matured bovine oocytes. Biol Reprod 50: 103-110

Ambrosini G, Andrisani A, Porcu E, Rebellato E, Revelli A, Caserta D, Cosmia E, Marci R, Moscarini M 2006: Oocytes cryopreservation: State of art (review). Reprod Toxicol 22: 250-262 
Arav A, Zeron Y, Leslie SB, Behboodi E, Anderson GB, Crowe JH 1996: Phase transition temperature and chilling sensitivity of bovine oocytes. Cryobiology 33: 589-599

Betteridge KJ 2006: Farm animal embryo technologies: Achievements and perspectives. Theriogenology 65: 905-913

Bielanski A, Bergeron H, Lau PCK, Devenisha J 2003: Microbial contamination of embryos and semen during long term banking in liquid nitrogen. Cryobiology 46: 146-152

Bielanski A, Nadin-Davis S, Sapp T, Lutze-Wallace C 2000: Viral contamination of embryos cryopreserved in liquid nitrogen. Cryobiology 40: 110-116

Bogliolo L, Ariu F, Fois S, Rosati I, Zedda MT, Leoni G, Succu S, Paua S, Ledda S 2007: Morphological and biochemical analysis of immature ovine oocytes vitrified with or without cumulus cells. Theriogenology 68: $1138-1149$

Chen SU, Lien YR, Chao KH, Ho HN, Yang YS, Lee TY 2003: Effects of cryopreservation on meiotic spindles of oocytes and its dynamics after thawing: clinical implications in oocyte freezing (review). Mol Cell Endocrinol 202: 101-107

Chian RC, Huang JY, Gilbert L, Son WY, Holzer H, Cui SJ, Buckett WM, Tulandi T, Tan SL 2009: Obstetric outcomes following vitrification of in vitro and in vivo matured oocytes. Fertil Steril 91: 2391-2398

Diez C, Duquea P, Goméz E, Hidalgoa CO, Tamargoa C, Rodríguez A, Fernández L, de la Vargab S, Fernández A, Facala N, Carbajob M 2002: Bovine oocyte vitrification before or after meiotic arrest: effects on ultrastructure and developmental ability. Theriogenology 64: 317-333

Fuku E, Kojima T, Shioya Y, Marcus GJ, Downey BR 1992: In vitro fertilization and development of frozenthawed bovine oocytes. Cryobiology 29: 485-492

Hlavicova J, Lopatarova M, Cech S 2010: Effect of two-step vitrification on developmental competence of in vitro and in vivo produced bovine embryos. Acta Vet Brno 79: S55-S61

Hou YP, Liu Y, Dai YP, Li R, Shi WQ, Wang HP, Wang LL, Li N, Zhu SE 2009: Improved parthenogenetic development of vitrified-warmed bovine oocytes activated with $9 \%$ ethanol plus 6-DMAP. Theriogenology 72: 643-649

Hyttel P, Vajta G, Callesen H 2000: Vitrification of bovine oocytes with the open pulled straw method: ultrastructural consequences. Mol Reprod Dev 56: 80-88

Im KS, Kang JK, Kim HS 1996: Effects of cumulus cells, different cryoprotectants, various maturation stages and preincubation before insemination on developmental capacity of frozen-thawed bovine oocytes. Theriogenology 47: 881-891

Jain JK, Paulson RJ 2006: Oocyte cryopreservation. Fertil Steril 86: S1037-S1046

Kubota C, Yang X, Dinnyes A, Todoroki J, Yamakuchi H, Mizoshita K, Inohae S, Tabara N 1998: In vitro and in vivo survival of frozen-thawed bovine oocytes after IVF, nuclear transfer, and parthenogenetic activation. Mol Reprod Dev 51: 281-286

Kuwayama M, Vajta G, Ieda S, Kato O 2005: Comparison of open and closed methods for vitrification of human embryos and the elimination of potential contamination. Reprod Biomed Online 11: 608-614

Larman MG, Sheehan CB, Gardner DK 2006: Vitrification of mouse pronuclear oocytes with no direct liquid nitrogen. Reprod Biomed Online 12: 66-69

Luna HS, Ferrari I, Rumpf B. R 2001: Influence of stage of maturation of bovine oocytes at time of vitrification on the incidence of diploid metaphase II at completion of maturation. Anim Reprod Sci 68: 23-28

Martino A, Songsasen N, Leibo SP 1996: Development into blastocysts of bovine oocytes cryopreserved by ultra-rapid cooling. Biol Reprod 54: 1059-1069

Mazur P (1970): Cryobiology: the freezing of biological system. Science 168: 929-949

Modina S, Beretta M, Lodde V, Lauria A, Luciano AM 2004: Cytoplasmic changes and developmental competence of bovine oocytes cryopreserved without cumulus cells. Eur J Histochem 48: 337-346

Morató R, Izquierdo R, Albarracín JL, Anguita B, Palomo MJ, Jiméez-Macedo AR, Paramio MT, Mogas T 2008a: Effects of pre-treating in vitro-matured bovine oocytes with the cytoskeleton stabilizing agent taxol prior to vitrification. Mol Reprod Dev 75: 191-201

Morató R, Izquierdo D, Paramio MT, Mogas T 2008b: Embryo development and structural analysis of in vitro matured bovine oocytes vitrified in flexipet denuding pipettes. Theriogenology 70: 1536-1543

Morató R, Izquierdo D, Paramio MT, Mogas T 2008c: Cryotops versus open-pulled straws (OPS) as carriers for the cryopreservation of bovine oocytes: Effects on spindle and chromosome configuration and embryo development. Cryobiology 57: 137-141

Quinn PJ 1985: A lipid-phase separation model of low-temperature damage to biological membranes. Cryobiology 22: 128-146

Stachecki JJ, Garrisi J, Sabino S, Caetano JP J, Wiemer KE, Cohen J 2008: A new safe, simple and successful vitrification method for bovine and human blastocysts. Reprod Biomed Online 17: 360-367

Vajta G, Holm P, Kuwayama M, Booth PJ, Jacobsen H, Greve T, Callesen H 1998: Open pulled straw (OPS) vitrification: a new way to reduce cryoinjuries of bovine ova and embryos. Mol Reprod Dev 51: 53-58

Vajta G, Nagy ZP, Cobo A, Conceicao J, Yovich J. 2009: Vitrification in assisted reproduction: myths, mistakes, disbeliefs and confusion. Reprod Biomed Online 19: 1-7 
Vieira AD, Mezzalira A, Barbieri DP, Lehmkuhl RC, Rubin MIB, Vajta G 2002: Calves born after open pulled straw vitrification of immature bovine oocytes. Cryobiology 45: 91-94

Zhou XL, Al Naib A, Sun DW, Lonergan P 2010: Bovine oocyte vitrification using the Cryotop method: Effect of cumulus cells and vitrification protocol on survival and subsequent development. Cryobiology 61: $66-72$ 